\title{
Accelerated formation of barium titanate by solid-state reaction in water vapour atmosphere
}

Takahiro Kozawa, Ayumu Onda, Kazumichi Yanagisawa*

Research Laboratory of Hydrothermal Chemistry, Faculty of Science, Kochi University, 2-5-1

Akebono-cho, Kochi 780-8520, Japan

*Corresponding author. Tel.: +81-88-844-8352; fax: +81-88-844-8362.

E-mail address: yanagi@kochi-u.ac.jp (K. Yanagisawa). 


\section{Abstract}

Barium titanate $\left(\mathrm{BaTiO}_{3}\right)$ powders were synthesized from commercially available raw materials $\left(\mathrm{BaCO}_{3}\right.$ and rutile) without particular mechanochemical processing by solid-state reactions in water vapour atmosphere. The formation rate of $\mathrm{BaTiO}_{3}$ was accelerated by water vapour and single phase of $\mathrm{BaTiO}_{3}$ was obtained by calcination at $700{ }^{\circ} \mathrm{C}$ for $4 \mathrm{~h}$ in water vapour atmosphere, though high temperature $\left(850{ }^{\circ} \mathrm{C}\right.$ for $\left.2.5 \mathrm{~h}\right)$ was required by calcinations in air to complete the reaction. The formation kinetics followed the Valensi-Carter equation, which suggested that the reaction proceeded by a diffusion controlled process. The apparent activation energy for the formation of $\mathrm{BaTiO}_{3}$ in air and water vapour atmosphere was estimated to be $361 \pm 20 \mathrm{~kJ} / \mathrm{mol}$ and $142 \pm 17 \mathrm{~kJ} / \mathrm{mol}$, respectively. Water vapour is considered to enhance thermal decomposition of $\mathrm{BaCO}_{3}$ and formation of $\mathrm{BaTiO}_{3}$ by attacking surface Ti-O-Ti bonds in $\mathrm{TiO}_{2}$, increasing partial pressure of $\mathrm{Ba}(\mathrm{OH})_{2}$, and producing vacancies in the $\mathrm{BaTiO}_{3}$ structure.

Keywords: Powders-solid state reaction; $\mathrm{BaTiO}_{3}$ and titanates; Water vapour 


\section{Introduction}

Barium titanate $\left(\mathrm{BaTiO}_{3}\right)$ is well-known electroceramics widely utilized for manufactures of piezoelectric actuators and multilayer ceramic capacitors (MLCCs) due to its excellent dielectric properties. $\mathrm{BaTiO}_{3}$ powders are conventionally prepared by solid-state reactions of barium carbonate $\left(\mathrm{BaCO}_{3}\right)$ and titanium dioxide $\left(\mathrm{TiO}_{2}\right)$ at temperatures above $1000{ }^{\circ} \mathrm{C}$. The high calcination temperature required by the solid-state reaction process leads to many disadvantages of the $\mathrm{BaTiO}_{3}$ powders, such as large particle size with a wide size distribution and high degree of particle agglomeration. Recent studies have clearly shown that the reduction of the particle size of the raw materials $\left(\mathrm{BaCO}_{3}\right.$ and $\left.\mathrm{TiO}_{2}\right)$ to submicrometer or even to nanoscale results in a significant decrease of the calcination temperatures. ${ }^{1-3}$ By using the submicrometer $\mathrm{BaCO}_{3}\left(d_{50}=0.17 \mu \mathrm{m}\right)$ and fine $\mathrm{TiO}_{2}\left(d_{50}=0.2 \mu \mathrm{m}\right)$, single phase of $\mathrm{BaTiO}_{3}$ was almost obtained at $900{ }^{\circ} \mathrm{C}$ for $6 \mathrm{~h} .{ }^{1}$ The formation of $\mathrm{BaTiO}_{3}$ by solid-state reactions of nanocrystalline $\mathrm{BaCO}_{3}$ and $\mathrm{TiO}_{2}$ powders was completed at $700-800{ }^{\circ} \mathrm{C} .{ }^{2-3}$ In addition, mechanochemical effects are known to be quite effective to reduce the calcination temperatures for solid-state reactions. ${ }^{4-7}$ Kong et al. ${ }^{7}$ milled the starting mixture in a planetary mill in air and obtained $\mathrm{BaTiO}_{3}$ by calcination of the milled mixture at $800{ }^{\circ} \mathrm{C}$ for $2 \mathrm{~h}$. The decrease of the calcination temperature provides the fine particle but usually lowers the crystallinity of the products.

On the other hand, it has been shown that the thermal decomposition of calcium carbonate $\left(\mathrm{CaCO}_{3}\right)$ is accelerated by water vapour. ${ }^{8-11}$ It is expected that the thermal decomposition of $\mathrm{BaCO}_{3}$ is also promoted by water vapour and the subsequent formation of $\mathrm{BaTiO}_{3}$ by solid-state reactions with $\mathrm{TiO}_{2}$ is accelerated. 
The aim of this study is to prepare $\mathrm{BaTiO}_{3}$ powders at low temperatures in water vapour atmosphere by solid-state reactions using commercially available raw materials without particular mechanochemical processing. In this paper, the influence of water vapour on the formation kinetics of $\mathrm{BaTiO}_{3}$ is reported and its formation mechanism is discussed.

\section{Experimental procedures}

The commercially available $\mathrm{BaCO}_{3}$ (Wako pure chemical industries, Japan, 99\% purity, $S_{\mathrm{BET}}=1.68$ $\mathrm{m}^{2} / \mathrm{g}, d_{\mathrm{BET}}=0.83 \mu \mathrm{m}$ ) and $\mathrm{TiO}_{2}$ (rutile, Wako, $99 \%$ purity, $S_{\mathrm{BET}}=5.60 \mathrm{~m}^{2} / \mathrm{g}, d_{\mathrm{BET}}=0.25 \mu \mathrm{m}$ ) with stoichiometric quantities were mixed in a stainless ball mill for $6 \mathrm{~h}$ at $280 \mathrm{rpm}$. The mixed powder $(0.1 \mathrm{~g})$ was calcined at $650-1000{ }^{\circ} \mathrm{C}$ for $0.5-12 \mathrm{~h}$ in air and water vapour atmosphere by a tubular furnace equipped with a water evaporator. Calcinations in air atmosphere were performed in stagnant condition. In water vapour atmosphere, distilled water was introduced at a flow rate of $2 \mathrm{~mL} / \mathrm{min}$ into the evaporator without a carrier gas to generate $100 \%$ water vapour atmosphere in the furnace. Flow rate of water vapour was estimated to be $2.5 \mathrm{~L} / \mathrm{min}$.

Crystalline phases in the products were identified by powder X-ray diffractions (XRD) obtained by a Rigaku Rotaflex RAD-RC diffractometer using $\mathrm{Cu} K \alpha$ radiation operating at voltage and current of $40 \mathrm{kV}$ and $100 \mathrm{~mA}$, respectively. Data were collected in the range of $5-80^{\circ}$ in $2 \theta / \theta$ scanning mode with a $0.02^{\circ}$ step and scanning speed of $4 \% \mathrm{~min}$. 
The amount of $\mathrm{BaTiO}_{3}$ in each sample was determined from XRD peak areas of $\mathrm{BaTiO}_{3}\left(\begin{array}{lll}1 & 0 & 1\end{array}\right) \quad\left(\begin{array}{lll}1 & 1\end{array}\right.$

0) and silicon (l 11 1) diffraction. Silicon (Sigma-Aldrich, USA, 99.999\% purity) was used as an internal standard. The calibration curve was previously obtained from the mixtures of silicon and pure $\mathrm{BaTiO}_{3}$ which was prepared by solid-state reaction at $800{ }^{\circ} \mathrm{C}$ for $12 \mathrm{~h}$, followed by calcination at $1200{ }^{\circ} \mathrm{C}$ for $6 \mathrm{~h}$ in air. $\mathrm{TiO}_{2}$ was used as a dilution agent. Data were collected in the range of $27-33^{\circ}$ in $2 \theta / \theta$ scanning mode with a $0.006^{\circ}$ step and scanning speed of $0.5^{\circ} / \mathrm{min}$.

The lattice constants were calculated by the least square method using silicon as an internal standard.

Data were collected in the range of $65-135^{\circ}$ in $2 \theta / \theta$ scanning mode with a $0.006^{\circ}$ step and scanning speed of $0.5^{\circ} / \mathrm{min}$. Specific surface area, $S_{\mathrm{BET}}$, was measured by the BET method using nitrogen with a Yuasa-ionics NOVA-1200 instrument. The equivalent BET diameter, $d_{\mathrm{BET}}$, was calculated by the following equation:

$$
d_{\mathrm{BET}}=6 / \rho S_{\mathrm{BET}}
$$

where $\rho$ is the density of $\mathrm{BaCO}_{3} 4.306 \mathrm{~g} / \mathrm{cm}^{3}$, rutile type $\mathrm{TiO}_{2} 4.250 \mathrm{~g} / \mathrm{cm}^{3}$ and $\mathrm{BaTiO}_{3} 6.012 \mathrm{~g} / \mathrm{cm}^{3}$.

\section{Results and discussion}

\subsection{Preparation of $\mathrm{BaTiO}_{3}$ powders by solid-state reactions}

The formation of $\mathrm{BaTiO}_{3}$ by solid-state reactions of $\mathrm{BaCO}_{3}$ and $\mathrm{TiO}_{2}$ involves the thermal decomposition of $\mathrm{BaCO}_{3}$, so that the forcible removing of $\mathrm{CO}_{2}$ gas from the reaction field might be accelerated the formation of $\mathrm{BaTiO}_{3}$. The preliminary experiments for solid-state reactions of $\mathrm{BaCO}_{3}$ and 
$\mathrm{TiO}_{2}$ were conducted at $750{ }^{\circ} \mathrm{C}$ for $2 \mathrm{~h}$ in stagnant air and $\mathrm{N}_{2}$ flowing atmosphere. $\mathrm{N}_{2}$ gas was introduced to generate $100 \% \mathrm{~N}_{2}$ gas flowing atmosphere in the furnace at the same flow rate of $2.5 \mathrm{~L} / \mathrm{min}$ with that for $100 \%$ water vapour atmosphere. As shown in Fig. 1, the products obtained in stagnant air and $\mathrm{N}_{2}$ flowing atmosphere gave the similar XRD patterns which showed that a large amount of $\mathrm{BaCO}_{3}$ remained and a small amount of $\mathrm{BaTiO}_{3}$ was formed. We considered that a gas flow for forcible removing of $\mathrm{CO}_{2}$ gas had little effects on the decomposition of $\mathrm{BaCO}_{3}$. Consequently, we examined the effect of water vapour atmosphere on the formation of $\mathrm{BaTiO}_{3}$ comparing with stagnant air atmosphere.

Fig. 2 shows the XRD patterns of the samples obtained by calcinations in air and water vapour atmosphere at $750{ }^{\circ} \mathrm{C}$ and $800{ }^{\circ} \mathrm{C}$ for $2 \mathrm{~h}$. In air atmosphere, the raw materials remained in large quantities even at $800{ }^{\circ} \mathrm{C}$. In contrast, the solid-state reaction of $\mathrm{BaCO}_{3}$ and $\mathrm{TiO}_{2}$ was accelerated by the injection of water vapour. $\mathrm{BaTiO}_{3}$ was obtained as a single phase at $750{ }^{\circ} \mathrm{C}$ for $2 \mathrm{~h}$ in water vapour atmosphere. Water vapour accelerated the thermal decomposition of the $\mathrm{BaCO}_{3}$ and then $\mathrm{BaTiO}_{3}$ was synthesized at lower temperatures.

In order to investigate the reaction kinetics and formation mechanism of $\mathrm{BaTiO}_{3}$, quantitative analysis of $\mathrm{BaTiO}_{3}$ in each sample was conducted by the XRD using the internal standard method. The formation ratios of $\mathrm{BaTiO}_{3}$ (fraction reacted: $\alpha$ ) are plotted against calcination time at various temperatures in Fig. 3 . The single phase of $\mathrm{BaTiO}_{3}$ was obtained in water vapour atmosphere by calcinations at $700{ }^{\circ} \mathrm{C}$ for $4 \mathrm{~h}$ and $750{ }^{\circ} \mathrm{C}$ for $2 \mathrm{~h}$. However, the $\mathrm{BaTiO}_{3}\left(\begin{array}{lll}1 & 0 & 1\end{array}\right)\left(\begin{array}{lll}1 & 1 & 0\end{array}\right) \mathrm{XRD}$ peak area of these samples was slightly lower than that of fully crystallized $\mathrm{BaTiO}_{3}$, which results in lower formation ratios of these samples than 
$100 \%$. The formation ratios of $\mathrm{BaTiO}_{3}$ always increased with increase in calcination temperatures and times. The formation ratio by the calcinations in air has not reached $50 \%$ at $750{ }^{\circ} \mathrm{C}$ for $12 \mathrm{~h}$, while that in water vapour atmosphere approached $100 \%$ at $700{ }^{\circ} \mathrm{C}$ within $12 \mathrm{~h}$.

Tagawa and Igarashi ${ }^{12}$ examined the kinetics of the solid-state reaction of strontium carbonate $\left(\mathrm{SrCO}_{3}\right)$ and $\mathrm{TiO}_{2}$ to form strontium titanate $\left(\mathrm{SrTiO}_{3}\right)$ by the Jander ${ }^{13}$ model and Valensi-Carter ${ }^{14,15}$ model based on the diffusion controlled process. The reaction mechanism proposed by Jander is the simple model of powder reactions by diffusion but the equation proposed by Valensi and Carter was derived without simplification. We applied the Valensi-Carter equation to our experimental data and determined the mechanism for the solid-state reaction between $\mathrm{BaCO}_{3}$ and $\mathrm{TiO}_{2}$ to form $\mathrm{BaTiO}_{3}$.

The Valensi-Carter equation is given as Eq. (2).

$$
\left\{z-[1+(z-1) \alpha]^{2 / 3}-(z-1)(1-\alpha)^{2 / 3}\right\} /(z-1)=k t
$$

where $z$ represents the volume of product formed per unit volume of reactant consumed, $\alpha$ the fraction reacted, $k$ the reaction rate constant, and $t$ the reaction time. In the case of the reaction of $\mathrm{BaCO}_{3}$ and $\mathrm{TiO}_{2}$ to form $\mathrm{BaTiO}_{3}, z$ is 0.600 . Fig. 4 shows the Valensi-Carter plots for the reaction of $\mathrm{BaCO}_{3}$ and $\mathrm{TiO}_{2}$. The linear relation was obtained for all data, which suggests that it is reasonable to conclude that the formation mechanism of $\mathrm{BaTiO}_{3}$ in both atmospheres is diffusion controlled process following the Valensi-Carter equation. From the slopes in Fig. 4, the reaction rate constant, $k$, was obtained. Arrhenius plots of $\ln k$ versus $1 / T$ as shown in Fig. 5 gave the apparent activation energy, $E_{\mathrm{a}}$, for the formation of $\mathrm{BaTiO}_{3}$ by the solid-state reactions and it was estimated to be $361 \pm 20 \mathrm{~kJ} / \mathrm{mol}$ and $142 \pm 17 \mathrm{~kJ} / \mathrm{mol}$ in air 
and water vapour atmosphere, respectively. By introducing water vapour, the apparent activation energy was drastically decreased. In other words, the diffusion of $\mathrm{Ba}^{2+}$ and $\mathrm{O}^{2-}$ ions through the $\mathrm{BaTiO}_{3}$ layer was accelerated by water vapour.

\subsection{Mechanism of accelerated reaction by water vapour}

The results shown in Fig. 2 clearly indicated that water vapour accelerated the thermal decomposition of $\mathrm{BaCO}_{3}$. Wang and Thomson ${ }^{10}$ described that adsorbed water vapour weakened $\mathrm{Ca}-\mathrm{CO}_{3}$ bond and the thermal decomposition of $\mathrm{CaCO}_{3}$ was accelerated by water vapour. Water vapour atmosphere similarly might play an important role to weaken the $\mathrm{Ba}-\mathrm{CO}_{3}$ bond, which resulted in acceleration of $\mathrm{BaCO}_{3}$ decomposition in water vapour atmosphere at lower temperatures in comparison with that in air. Furthermore, the lower $\mathrm{CO}_{2}$ partial pressure in the water vapour might enhance the decomposition of $\mathrm{BaCO}_{3}$ decomposition.

We previously showed that water adsorbed on the surface of amorphous titania particles catalyzed the rearrangement of the $\mathrm{TiO}_{6}$ octahedra to accelerate the crystallization of amorphous titania to anatase. ${ }^{16,17}$ MacKenzie ${ }^{18}$ reported that water vapour assisted sintering of rutile type $\mathrm{TiO}_{2}$ and presented an assumption of the formation of transient hydroxy-species such as $\mathrm{Ti}(\mathrm{OH})_{2}{ }^{2+}$ on the surface of the particles. The same effect is expected for the calcinations in water vapour atmosphere in this study. It is considered that water vapour attacks Ti-O-Ti bonds of rutile surface to promote rotation and movement of $\mathrm{TiO}_{6}$ octahedra, and $\mathrm{Ba}^{2+}$ and $\mathrm{O}^{2-}$ ions which have already formed by the decomposition of $\mathrm{BaCO}_{3}$, easily react 
with $\mathrm{TiO}_{6}$ octahedra to form $\mathrm{BaTiO}_{3}$. Most of formed hydroxyl groups are simultaneously eliminated as $\mathrm{H}_{2} \mathrm{O}$ molecule by the rearrangement of $\mathrm{TiO}_{6}$ octahedra to the perovskite structure of $\mathrm{BaTiO}_{3}$.

The formation of $\mathrm{BaTiO}_{3}$ must be limited to the $\mathrm{BaCO}_{3} / \mathrm{TiO}_{2}$ contact points. The observed decrease of the reaction temperature in water vapour atmosphere even by using the relatively coarse particles $\left(\mathrm{BaCO}_{3}\right.$ $0.83 \mu \mathrm{m}$ and $\mathrm{TiO}_{2} 0.25 \mu \mathrm{m}$ ) may imply that a $\mathrm{Ba}$ species is efficiently supplied over the entire $\mathrm{TiO}_{2}$ particle surface in water vapour atmosphere. One possible mechanism is gas phase transport. It is reported that the volatility of the barium oxide $(\mathrm{BaO})$ is greatly increased by the presence of water vapour due to the formation of volatile hydroxide $\left(\mathrm{Ba}(\mathrm{OH})_{2}\right)$ vapour ${ }^{19-21}$ and $\mathrm{Ba}(\mathrm{OH})_{2}$ vapour pressure is given as Eq. $(3){ }^{21}$

$$
\ln K_{\mathrm{p}}=-16792.3 / T+4.94
$$

where $K_{\mathrm{p}}=p\left(\mathrm{Ba}(\mathrm{OH})_{2}\right) / p\left(\mathrm{H}_{2} \mathrm{O}\right)$. Though the Eq. (3) was obtained at high temperatures over $1000{ }^{\circ} \mathrm{C}$, we can estimate $\mathrm{Ba}(\mathrm{OH})_{2}$ partial pressure to be $2.2 \times 10^{-5}$ atm at $800{ }^{\circ} \mathrm{C}$ from the Eq. (3). This value is not negligible and gas phase transport of $\mathrm{Ba}(\mathrm{OH})_{2}$ could become important when the solid-state reaction occurs in water vapour atmosphere. Accordingly, the surface diffusion of barium may be enhanced in water vapour atmosphere.

The formation of $\mathrm{BaTiO}_{3}$ by solid-state reactions is diffusion controlled process as described above, and is explained by coupled diffusion of $\mathrm{Ba}^{2+}$ and $\mathrm{O}^{2-}$ ions in the $\mathrm{BaTiO}_{3}$ crystal lattice. ${ }^{3,22-24}$ Mutin and Niepce ${ }^{23}$ suggested vacancy mechanism for diffusion of $\mathrm{Ba}^{2+}$ and $\mathrm{O}^{2-}$ ions. It is reported that the $\mathrm{BaTiO}_{3}$ powders prepared by hydrothermal method contain a large amount of proton in the oxygen sublattice and 
the proton defects are compensated by the simultaneously formation of barium and titanium vacancies. ${ }^{25}$

These defects might be formed by the solid-state reactions in water vapour atmosphere, which can explain the enhanced solid-state diffusion of barium. $\mathrm{Ba}^{2+}$ vacancies $\left(\left(\mathrm{Ba}_{1-x} \mathrm{H}_{2 x}\right) \mathrm{TiO}_{3}\right)$ might be formed in the $\mathrm{BaTiO}_{3}$ structure when $\mathrm{Ba}^{2+}$ ions are diffused into the space between $\mathrm{TiO}_{6}$ octahedra with hydroxyl groups, though most of formed hydroxyl groups are simultaneously eliminated as $\mathrm{H}_{2} \mathrm{O}$ molecule by the rearrangement of $\mathrm{TiO}_{6}$ octahedra to form $\mathrm{BaTiO}_{3}$. As a result, the formation of $\mathrm{Ba}^{2+}$ vacancies facilitates the diffusion of $\mathrm{Ba}^{2+}$ ions by vacancy mechanism. On the other hand, it is also well known that sintering of $\mathrm{BaTiO}_{3}$ in reducing atmosphere forms $\mathrm{O}^{2-}$ ion vacancy $\left(\mathrm{BaTiO}_{3-x}\right)$ with a valence reduction of titanium from $\mathrm{Ti}^{4+}$ into $\mathrm{Ti}^{3+}$. In water vapour atmosphere that gives a reducing atmosphere compared with in air atmosphere, $\mathrm{O}^{2-}$ ion vacancy with the reduction of titanium ion might be formed in the $\mathrm{BaTiO}_{3}$ structure. This $\mathrm{O}^{2-}$ vacancy also promotes the diffusion of $\mathrm{O}^{2-}$ ions. Thus, it is considered that the diffusion of $\mathrm{Ba}^{2+}$ and $\mathrm{O}^{2-}$ ions to the $\mathrm{TiO}_{2}$ reaction front through the $\mathrm{BaTiO}_{3}$ layer is accelerated by vacancy mechanism with three different vacancies formed in water vapour atmosphere.

\subsection{Powder properties and tetragonality}

The specific surface area and particle size of selected $\mathrm{BaTiO}_{3}$ powders prepared in this study are shown in Table 1. The results show that $\mathrm{BaTiO}_{3}$ powders with the same or smaller particle size in comparison with those obtained in air were prepared in water vapour atmosphere by calcinations at lower temperatures for a shorter time. For example, the particle size of $\mathrm{BaTiO}_{3}$ powder obtained by calcination 
at $750{ }^{\circ} \mathrm{C}$ for $2 \mathrm{~h}$ in water vapour atmosphere was estimated to be $0.24 \mu \mathrm{m}$ from its specific surface area, but $0.25 \mu \mathrm{m}$ by calcination at $850^{\circ} \mathrm{C}$ for $3 \mathrm{~h}$ in air.

Fig. 6 shows the tetragonality $(c / a)$ of $\mathrm{BaTiO}_{3}$ obtained by calcinations at various temperatures for 12 $\mathrm{h}$ in air and water vapour atmosphere. $\mathrm{BaTiO}_{3}$ was obtained as a single phase except for the sample obtained by calcination at $750{ }^{\circ} \mathrm{C}$ in air. In both atmospheres, the tetragonality of $\mathrm{BaTiO}_{3}$ increased with an increase in the calcination temperatures, which is explained by the increase of $\mathrm{BaTiO}_{3}$ crystallinity with increasing calcination temperatures. On the other hand, the tetragonality of $\mathrm{BaTiO}_{3}$ obtained in water vapour atmosphere was higher than that in air, and reached 1.0105 , close to 1.011 of the $\mathrm{BaTiO}_{3}$ single crystal (JCPDS No. 05-0626), by calcination at $850{ }^{\circ} \mathrm{C}$. This result indicates that the crystallinity of $\mathrm{BaTiO}_{3}$ is increased by water vapour.

\section{Conclusions}

$\mathrm{BaTiO}_{3}$ powders were prepared by solid-state reactions of $\mathrm{BaCO}_{3}$ and $\mathrm{TiO}_{2}$ in air and water vapour atmosphere. The formation of $\mathrm{BaTiO}_{3}$ was accelerated by water vapour and $\mathrm{BaTiO}_{3}$ powders with the same or smaller particle size in comparison with those obtained in air were prepared in water vapour atmosphere by calcinations at lower temperatures for a shorter time. The solid-state reaction to form $\mathrm{BaTiO}_{3}$ obeyed the Valensi-Carter equation, which suggested that the reaction proceeded by a diffusion controlled process. The apparent activation energy for the formation of $\mathrm{BaTiO}_{3}$ in water vapour atmosphere was estimated to be $142 \pm 17 \mathrm{~kJ} / \mathrm{mol}$, much lower than that in air $(361 \pm 20 \mathrm{~kJ} / \mathrm{mol})$. It is 
considered that water vapour has following effects to accelerate the formation of $\mathrm{BaTiO}_{3}$; (1) acceleration of $\mathrm{BaCO}_{3}$ decomposition, (2) acceleration of $\mathrm{BaTiO}_{3}$ formation by surface attacking of water at the $\mathrm{TiO}_{2}$ reaction front and by gas phase transport of $\mathrm{Ba}(\mathrm{OH})_{2}$, and (3) acceleration of the diffusion of $\mathrm{Ba}^{2+}$ and $\mathrm{O}^{2-}$ ions in the $\mathrm{BaTiO}_{3}$ layer by formation of vacancies in the $\mathrm{BaTiO}_{3}$ structure. 


\section{References}

1. Hennings, D. F. K., Schreinemacher, B. S. and Schreinemacher, H., Solid-state preparation of $\mathrm{BaTiO}_{3}$-based dielectrics, using ultrafine raw materials. J. Am. Ceram. Soc., 2001, 84, 2777-2782.

2. Buscaglia, M. T., Bassoli, M., Buscaglia, V. and Alessio, R., Solid-state synthesis of ultrafine $\mathrm{BaTiO}_{3}$ powders from nanocrystalline $\mathrm{BaCO}_{3}$ and $\mathrm{TiO}_{2}$. J. Am. Ceram. Soc., 2005, 88, 2374-2379.

3. Buscaglia, M. T., Bassoli, M., Buscaglia, V. and Vormberg, R., Solid-state synthesis of nanocrystalline $\mathrm{BaTiO}_{3}$ : reaction kinetics and powder properties. J. Am. Ceram. Soc., 2008, 91, 2862-2869.

4. Gomez-Yañez, C., Benitez, C. and Balmori-Ramirez, H., Mechanical activation of the synthesis reaction of $\mathrm{BaTiO}_{3}$ from a mixture of $\mathrm{BaCO}_{3}$ and $\mathrm{TiO}_{2}$ powders. Ceram. Int., 2000, 26, 271-277.

5. Berbenni, V., Marini, A. and Bruni, G., Effect of mechanical milling on solid state formation of $\mathrm{BaTiO}_{3}$ from $\mathrm{BaCO}_{3}-\mathrm{TiO}_{2}$ (rutile) mixtures. Thermochim. Acta, 2001, 374, 151-158.

6. Yanagawa, R., Senna, M., Ando, C., Chazono, H. and Kishi, H., Preparation of $200 \mathrm{~nm} \mathrm{BaTiO}$ particles with their tetragonality 1.010 via a solid-state reaction proceeded by agglomeration-free mechanical activation. J. Am. Ceram. Soc., 2007, 90, 809-814.

7. Kong, L. B., Ma, J., Huang, H., Zhang, R. F. and Que, W. X., Barium titanate derived from mechanochemically activated powder. J. Alloys Comp., 2002, 337, 226-230.

8. MacIntire, W. H. and Stansel, T. B., Steam catalysis in calcinations of dolomite and limestone fines. Ind. Eng. Chem., 1953, 45, 1548-1555. 
9. Burnham, A. K., Stubblefield, C. T. and Campbell, J. H., Effects of gas environmental reactions in Colorado oil shale. Fuel, 1980, 59, 871-877.

10. Wang, Y. and Thomson, W. J., The effects of steam and carbon dioxide on calcite decomposition using dynamic X-ray diffraction. Chem. Eng. Sci., 1995, 50, 1373-1382.

11. Agnew, J., Hampartsoumian, E., Jones, J. M. and Nimmo, W., The simultaneous calcination and sintering of calcium based sorbents under a combustion atmosphere. Fuel, 2000, 79, 1515-1523.

12. Tagawa, H. and Igarashi, K., Reaction of strontium carbonate with anatase and rutile. J. Am. Ceram. Soc., 1986, 69, 310-314.

13. Jander, W., Reaction in the solid state at high temperature I. Rate of reaction for an endothermic change. Z. Anorg. Allg. Chem., 1927, 163, 1-30.

14. Carter, R. E., Kinetic model for solid-state reactions. J. Chem. Phys., 1961, 34, 2010.

15. Frade, J. R. and Cable, M., Reexamination of the basic theoretical model for the kinetics of solid-state reaction. J. Am. Ceram. Soc., 1992, 75, 1949-1957.

16. Yanagisawa, K., Yamamoto, Y., Feng, Q. and Yamasaki, N., Formation mechanism of fine anatase crystals from amorphous titania under hydrothermal conditions. J. Mater. Res., 1998, 13, 825-829.

17. Yanagisawa, K. and Ovenstone, J., Crystallization of anatase from amorphous titania using the hydrothermal technique: effects of starting material and temperature. J. Phys. Chem. B, 1999, 103, 7781-7787. 
18. MacKenzie, K. J. D., The calcination of titania VII. Sintering of rutile. Trans. J. Brit. Ceram. Soc., 1975, 74, 127-134.

19. Stafford, F. E. and Berkowits, J., Mass-spectrometric study of the reaction of water vapor with solid barium oxide. J. Chem. Phys., 1964, 40, 2963-2969.

20. Sasamoto, T., Mizushima, K. and Sata, T., Transpiration study of the reaction of water vapor with barium oxide. Bull. Chem. Soc. Japan, 1979, 52, 2127-2129.

21. Ali (Basu), M., Mishra, R., Kerkar, A. S., Bharadwaj, S. R. and Das, D., Gibbs energy of formation of $\mathrm{Ba}(\mathrm{OH})_{2}$ vapor species using the transpiration technique. J. Nucl. Mater., 2001, 289, 243-246.

22. Beauger, A., Mutin, J. C. and Niepce, J. C., Synthesis reaction of metatitanate $\mathrm{BaTiO}_{3}$ Part 2 Study of solid-solid reaction interfaces. J. Mater. Sci., 1983, 18, 3543-3550.

23. Mutin, J. C. and Niepce, J. C., About stoichiometry of polycrystalline $\mathrm{BaTiO}_{3}$ synthesized by solid-solid reaction. J. Mater. Sci. Lett., 1984, 3, 591-592.

24. Graff, A., Senz, S., Voltzke, D., Abicht, H.-P. and Hesse, D., Microstructure evolution during $\mathrm{BaTiO}_{3}$ formation by solid-state reactions on rutile single crystal surfaces J. Eur. Ceram. Soc., 2005, 25, 2201-2206.

25. Hennings, D. F. K., Metzmacher, C. and Schreinemacher, B. S., Defect chemistry and microstructure of hydrothermal barium titanate. J. Am. Ceram. Soc., 2001, 84, 179-182. 


\section{Figure captions}

Fig. 1. XRD patters of the samples obtained by solid-state reaction at $750{ }^{\circ} \mathrm{C}$ for $2 \mathrm{~h}$ in (a) stagnant air and (b) $\mathrm{N}_{2}$ atmosphere.

Fig. 2. XRD patterns of the samples obtained by solid-state reactions at $750{ }^{\circ} \mathrm{C}$ and $800{ }^{\circ} \mathrm{C}$ for $2 \mathrm{~h}$ in (a) air and (b) water vapour atmosphere.

Fig. 3. Plots of fraction reacted of $\mathrm{BaTiO}_{3}(\alpha)$ obtained in (a) air and (b) water vapour atmosphere versus calcination time at various temperatures. Solid symbols show that the product is the $\mathrm{BaTiO}_{3}$ single phase according to XRD.

Fig. 4. Kinetics according to Valensi-Carter equation for reaction of $\mathrm{BaCO}_{3}$ and $\mathrm{TiO}_{2}$ in (a) air and (b) water vapour atmosphere.

Fig. 5. Arrhenius plot for $\mathrm{BaTiO}_{3}$ formation.

Fig. 6. Tetragonality of $\mathrm{BaTiO}_{3}$ as a function of calcination temperature for $12 \mathrm{~h}$. 
Table 1. Specific surface area and corresponding particle size of $\mathrm{BaTiO}_{3}$ powders

\begin{tabular}{clccc}
\hline Sample & $\begin{array}{c}\text { Calcination } \\
\text { conditions }\end{array}$ & Atmosphere & $S_{\mathrm{BET}}\left(\mathrm{m}^{2} / \mathrm{g}\right)$ & $d_{\mathrm{BET}}(\mu \mathrm{m})$ \\
\hline 1 & $800^{\circ} \mathrm{C} / 12 \mathrm{~h}$ & Air & 3.36 & 0.30 \\
2 & $850^{\circ} \mathrm{C} / 3 \mathrm{~h}$ & Air & 4.07 & 0.25 \\
3 & $750^{\circ} \mathrm{C} / 2 \mathrm{~h}$ & Water vapour & 4.14 & 0.24 \\
4 & $750^{\circ} \mathrm{C} / 12 \mathrm{~h}$ & Water vapour & 2.99 & 0.33 \\
5 & $800^{\circ} \mathrm{C} / 2 \mathrm{~h}$ & Water vapour & 4.04 & 0.25 \\
\hline
\end{tabular}


Fig. 1.

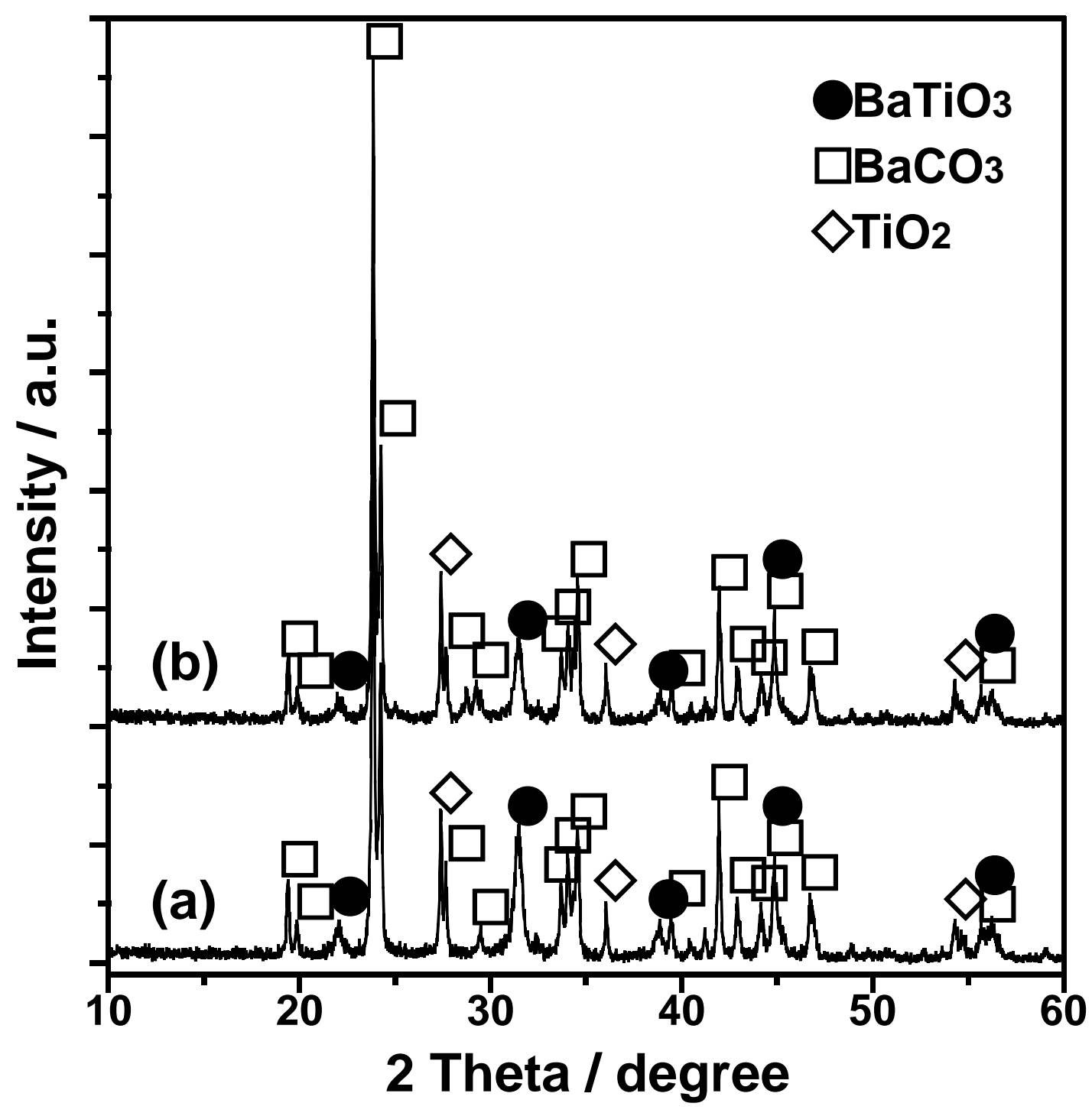


Fig. 2.
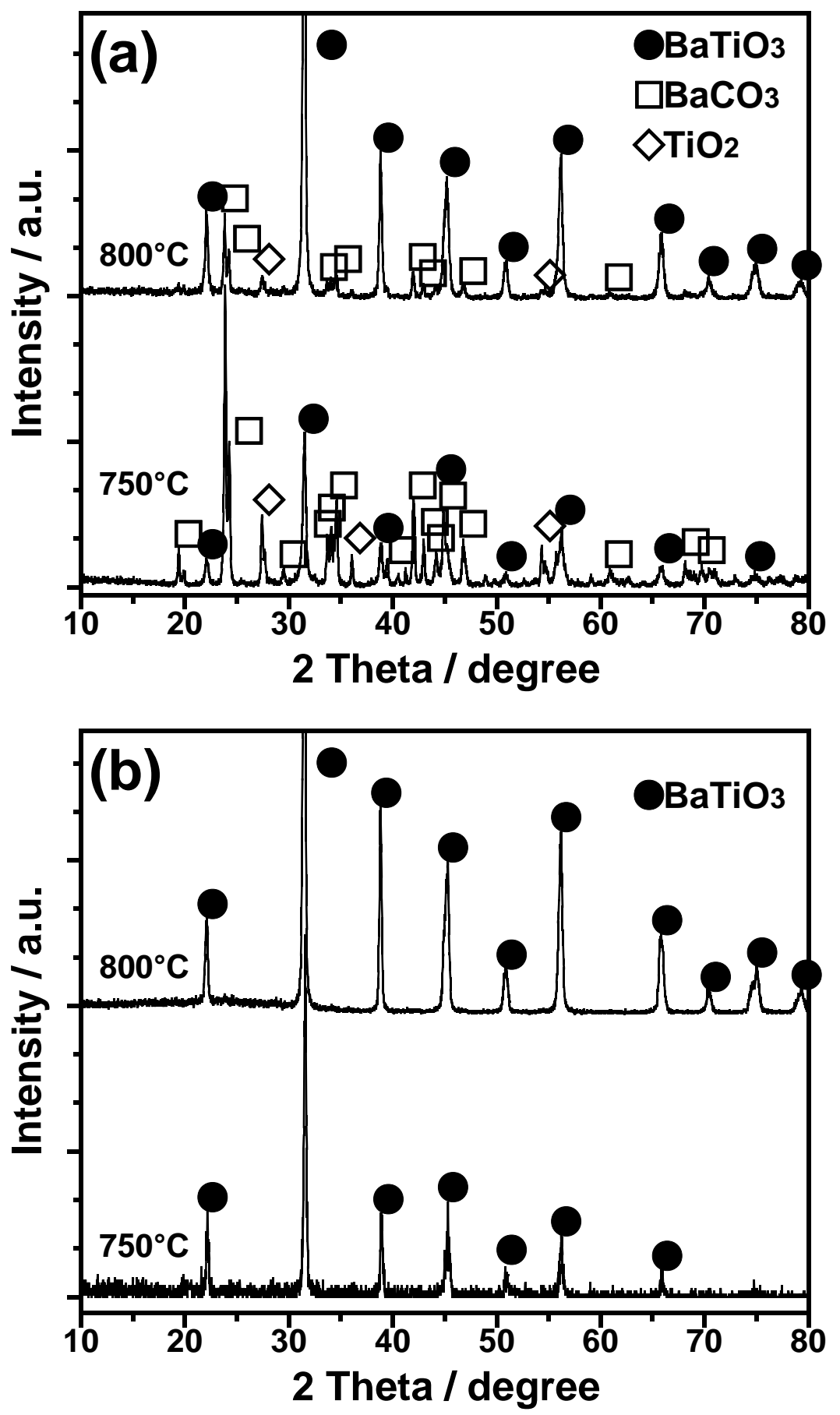
Fig. 3.

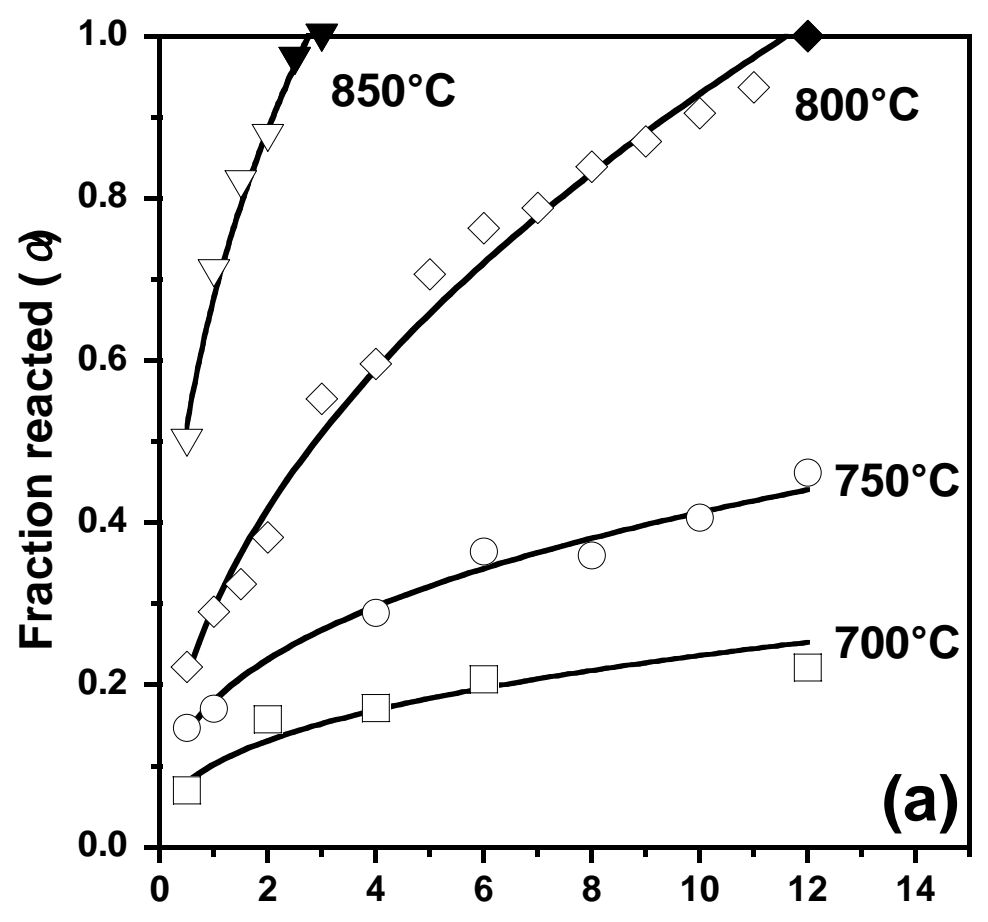

Calcination time $/ \mathrm{h}$

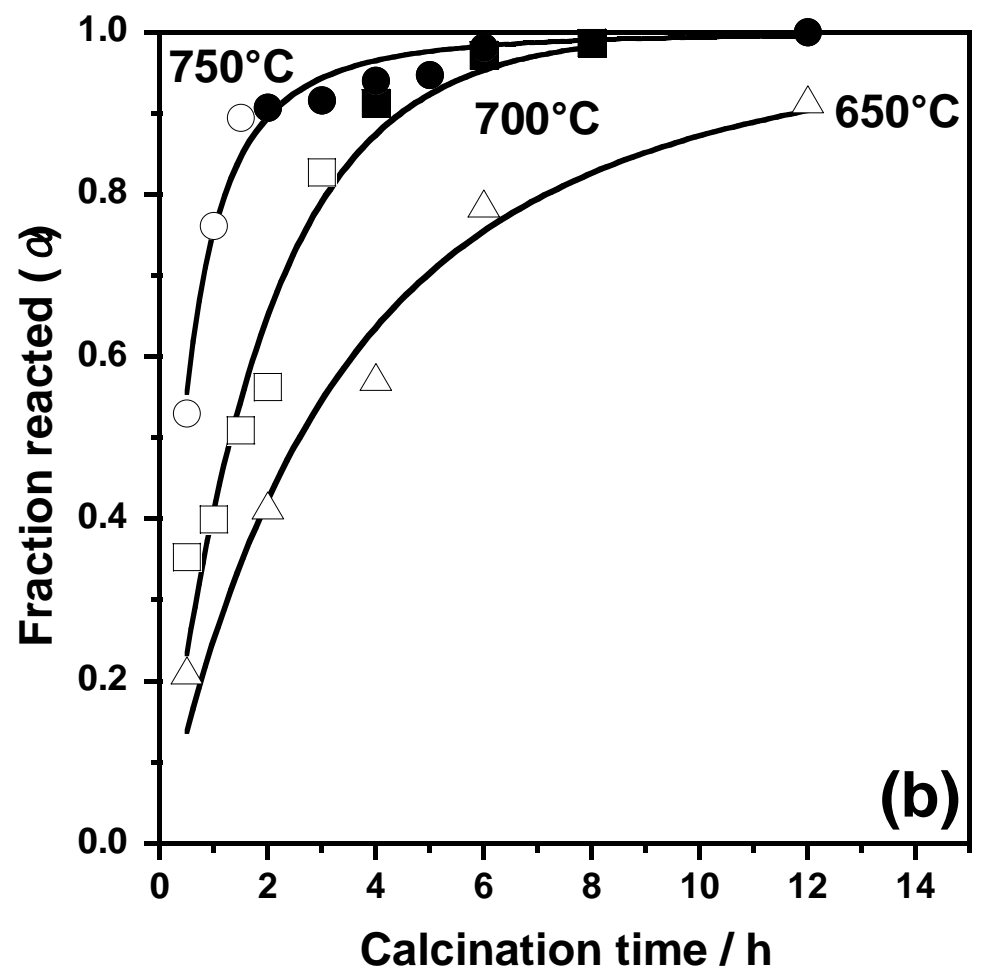


Fig. 4.
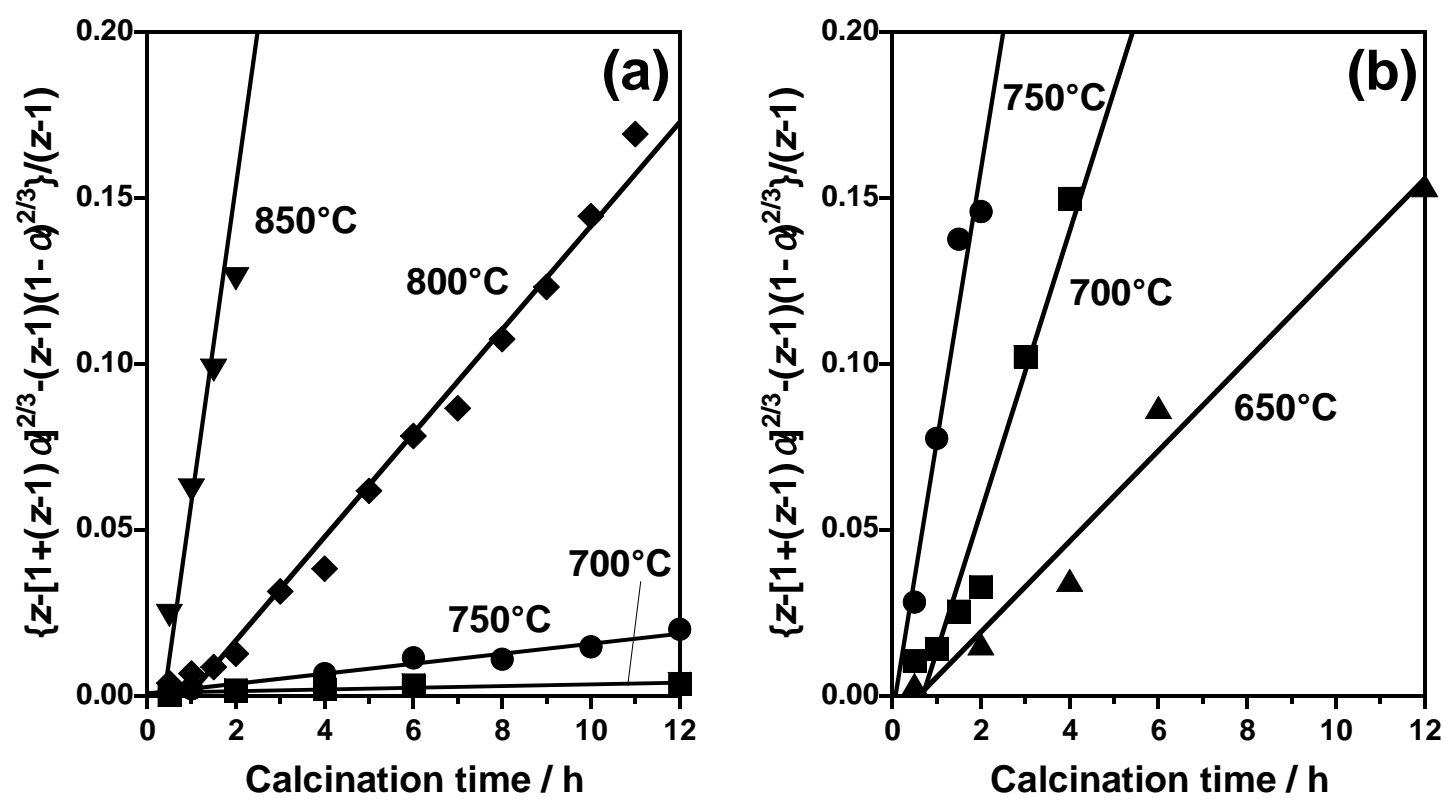
Fig. 5.

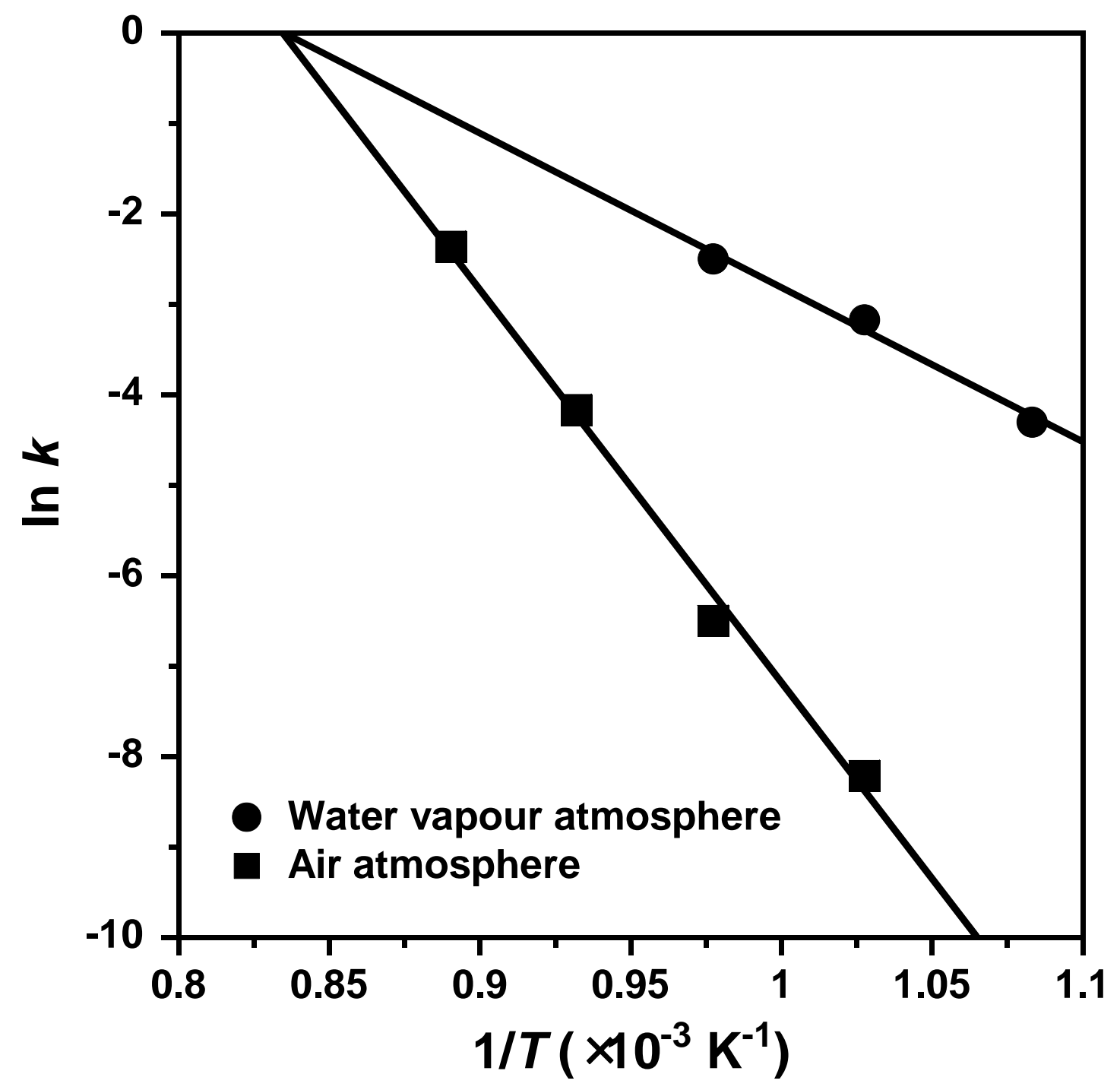


Fig. 6.

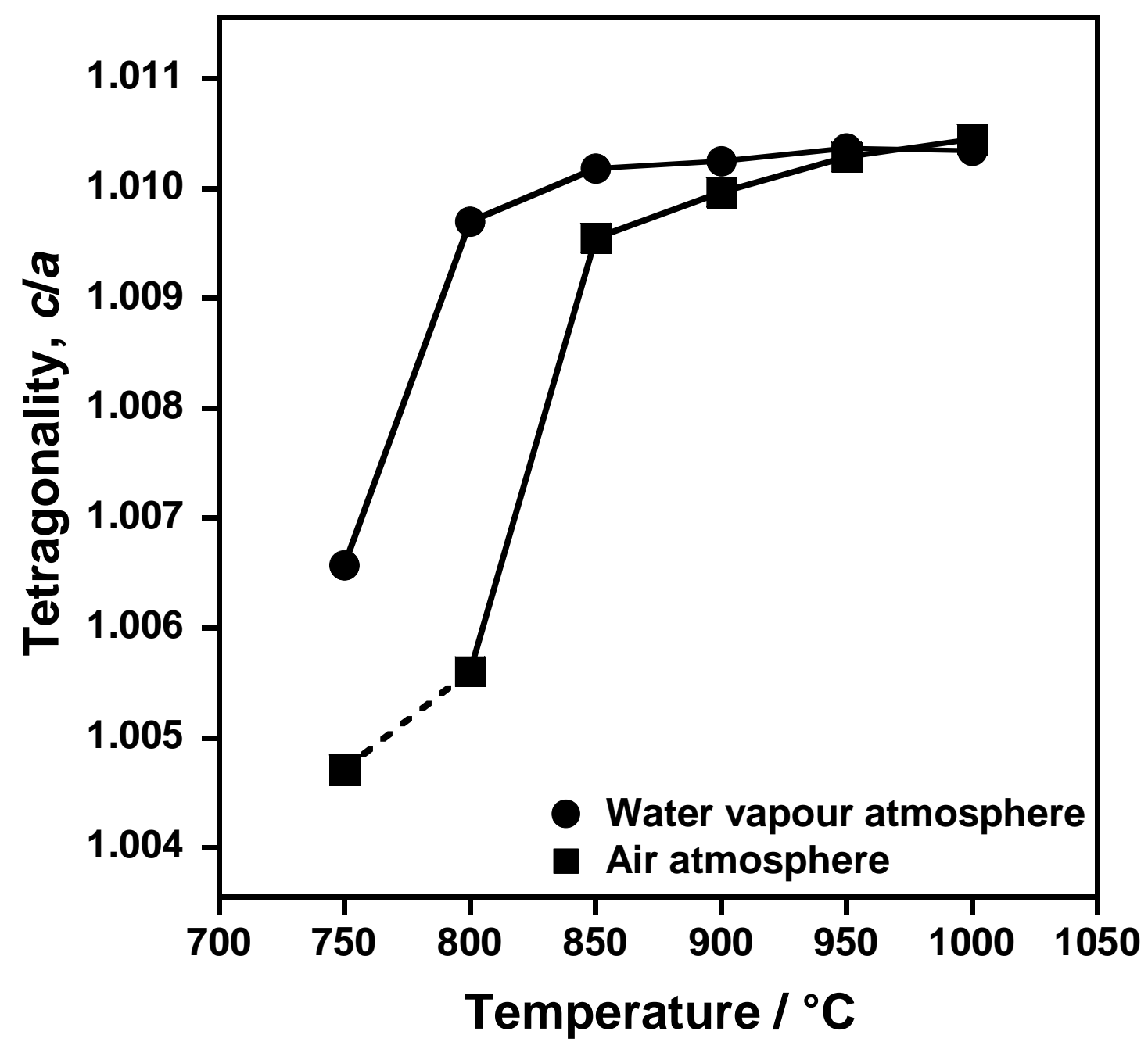

